\title{
Experimental study on spray characteristics of coal to liquid fuel under different injection pressures
}

\author{
Hucheng Zhang, Xincheng Tang, Zhiwei Jin, Xinqi Qiao* \\ Key Laboratory of Power Machinery and Engineering of Ministry of Education, School of \\ Mechanical Engineering, Shanghai Jiao Tong University, shanghai, P.R.China \\ ${ }^{*}$ Corresponding author email : qiaoxinqi@sjtu.edu.cn
}

\begin{abstract}
In this study, the spray characteristics of coal to liquid fuel were studied by high-speed photography and compared with petroleum diesel (PD), including diesel from direct coal liquefaction (DDCL) and diesel from indirect coal liquefaction (DICL). Spray characteristics parameters such as spray penetration, spray front speed, spray area and spray cone angle were compared in a constant volume bomb under different injection pressures. The results show that the droplet diameter of coal to liquid (CTL) fuel is smaller than that of PD due to lower viscosity and surface tension. The spray penetration and spray front speed of coal to liquid fuel is smaller than that of petroleum diesel. However, the coal to liquid fuel has larger spray area and spray cone angle compared with PD. Interestingly, the spray penetration, spray area and spray cone angle of DDCL is all larger than that of DICL. The four spray characteristics parameters of the spray increase as the injection pressure increases. The higher the injection pressure, the smaller the fuel injection delay. It is also found that the maximum spray front velocity of coal to liquid fuel is earlier than PD.
\end{abstract}

\section{Keywords}

coal to liquid, spray penetration, spray cone angle, droplet diameter.

\section{Introduction}

Diesel engines are the major prime movers in the transportation sectors. [1] According to the British Petroleum Statistical Review of World energy [2], the oil reserves in 2019 accounted for 50 years of current production. In the next years, oil still plays a key role in the transportation industry. [3] The combustion process of diesel engine depends on the atomization, evaporation and mixing process of fuel. As one of the key injection parameters, the injection pressure plays an important role in the breakup and atomization of oil spray.

Rich in coal while poor in oil is the distinctive energy structure in china. The coal reserve has reached $5.9 \times 10^{12} \mathrm{t}$, accounting for more than $90 \%$ of the total fossil energy. [4] Therefore, coal to liquid (CTL) is one of reasonable alternative fuel to relieve oil crisis. There are three typical methods of CTL: diesel from direct coal liquefaction (DDCL), diesel from indirect coal liquefaction (DICL) and high temperature pyrolysis. [5] High temperature pyrolysis of coal has been basically eliminated due to high reaction requirements and low yield, while direct and indirect coal liquefaction technologies have been relatively mature and have been industrialized.

Research on engine spray characteristics is mainly carried out by means of optical imaging technology and visualization test equipment. Hiroyasu and Arai [6] have drawn up an empirical formula for calculating the spray penetration distance through a large number of experimental studies. Although there is no correlation formula for CTL at present, the qualitative analysis of CTL can be made by the spray penetration formula of diesel fuel.

$0<\mathrm{t}<t_{b}$ : 


$$
\begin{aligned}
S & =0.39\left(\frac{2 \Delta P}{\rho_{l}}\right)^{0.5} t \\
\mathrm{t}>t_{b} & : \\
S & =2.95\left(\frac{\Delta P}{\rho_{a}}\right)^{0.25}(D t)^{0.5} \\
t_{b} & =28.65 \frac{\rho_{l} D}{\left(\rho_{a} \Delta P\right)^{0.5}}
\end{aligned}
$$

Where, $\Delta \mathrm{P}$ is the difference between the injection pressure and the back pressure in the cylinder, $\rho_{l}$ is the fuel density, $\rho_{a}$ is the gas density in the cylinder, $\mathrm{D}$ is the diameter of the injection hole, $t$ is the time from the beginning of injection to the calculation point, $t_{b}$ is the breaking time of oil beam.

The empirical formula of Sauter mean diameter (SMD) $\bar{x}$ of fuel droplet distribution is also given:

$$
\bar{x}=2.33 \times 10^{-3}(\Delta P)^{-0.135} \rho_{a}^{0.121} Q^{0.131}
$$

Where, $\Delta P$ is the difference between the injection pressure and the back pressure in the cylinder, $Q$ is the fuel volume injected into the cylinder in a single injection. It can be seen that the higher the injection pressure is, the smaller the Sauter mean diameter of the oil droplet is. Chen et al [7] used the gasifying sprayer to study the relationship between fuel spray cone angle and viscosity, and found that the spray cone angle increased with the decrease of liquid viscosity. El-Beshbeeshy et al [8] studies showed that fuel spray penetration and SMD had little correlation with fuel viscosity. When the fuel viscosity difference was $45 \%$, the change of spray penetration distance was only $3 \%$. Tabata and [9] used single hole injector to study the effect of fuel viscosity and surface tension on spray particle size. The SMD at the area $70 \mathrm{~mm}$ away from the nozzle along the injector axis was measured by laser diffraction technique. The results showed that the SMD increases with the viscosity and surface tension of the fuel. Chang and Farrell [10] were used to simulate the engine cylinder environment using constant volume bomb to study the fuel spray law. The study showed that fuel viscosity had no obvious effect on fuel injection rate; in the case of non evaporative spray, the effect of fuel viscosity on spray penetration is limited. At the early stage of injection, the spray cone angle of low viscosity fuel was larger than that of high viscosity fuel. The spray area of low viscosity fuel per unit mass was larger than that of high viscosity fuel, and the conclusion of SMD was the same as that of Tabata.

However, there are few comparative studies on the spray characteristics of DDCL and DICL. In this paper, high speed photography is used to study the spray characteristics of different fuels on the constant volume bomb test platform. The macroscopic spray characteristics of different fuels under different spray parameters are obtained by comparing the spray images under different injection pressures. The difference of micro spray between CTL and petroleum diesel is studied by laser diffraction particle size analyzer.

\section{Material and Methods}

The fuel spray test bench is shown in Figure 1. It consists of three parts: high pressure common rail injection system, constant volume bomb system and high-speed photography system (Memrecam HX-6). High pressure common rail fuel injection system produces highpressure fuel and fuel injection through a single hole injector. Constant volume bomb system 
provides a certain volume of backpressure. The length of the inner cavity of the constant volume bomb is $107 \mathrm{~mm}$, the visible range is $100 \mathrm{~mm}$, the maximum withstand voltage is 35 $\mathrm{MPa}$. The main test equipment for the micro spray is the high-speed spray particle size analyzer. The particle size analyzer is based on the laser diffraction method to measure the spray particle size. The particle size range measured by the high speed spray particle analyzer is 0.1 um-2080 um. The physical parameters of the test fuel are shown in the Table 1.

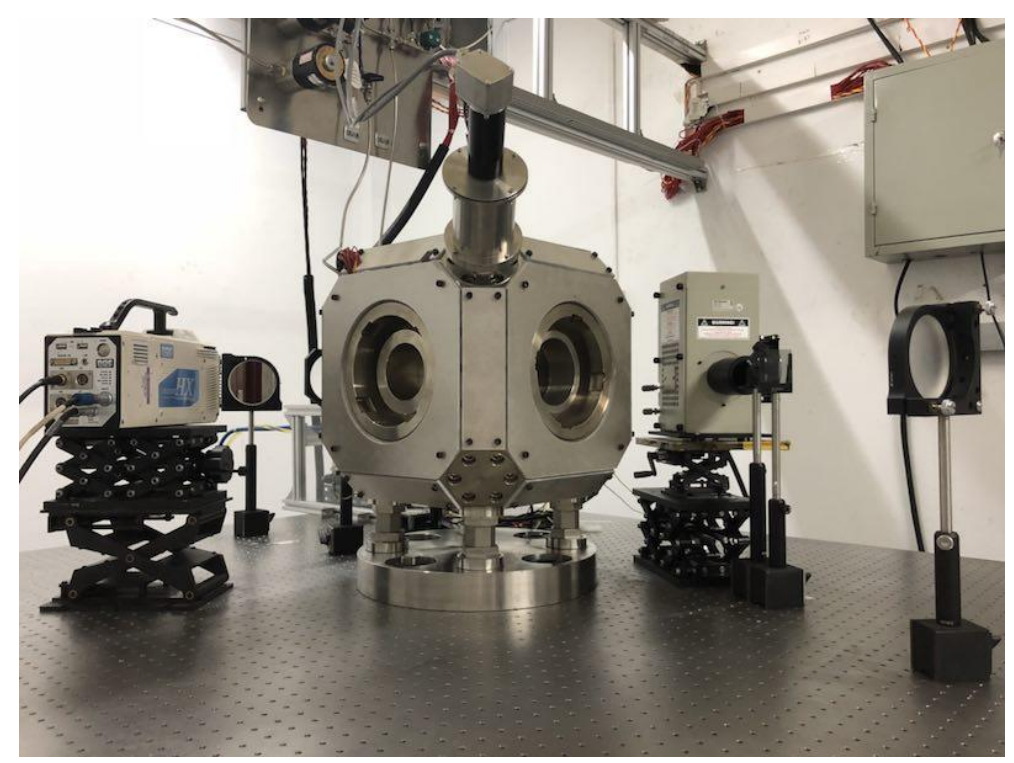

Figure 1 Fuel spray test bench

Table 1 Physical properties of test fuel

\begin{tabular}{c|ccc}
\hline Fuel property & DDCL & DICL & PD \\
\hline Density $\left(20^{\circ} \mathrm{C}\right) /(\mathrm{g} / \mathrm{cm} 3)$ & 0.849 & 0.767 & 0.834 \\
Kinematic viscosity $\left(20^{\circ} \mathrm{C}\right) /(\mathrm{mm} 2 / \mathrm{s})$ & 2.5 & 3.2 & 4.4 \\
Surface tension $\left(20^{\circ} \mathrm{C}\right) /(\mathrm{mN} / \mathrm{m})$ & 26.7 & 25.9 & 27.9 \\
Flash point $/\left({ }^{\circ} \mathrm{C}\right)$ & 66 & 63 & 68 \\
Sulfur content $/(\mu \mathrm{g} / \mathrm{g})$ & $<0.2$ & $<0.2$ & 4.48 \\
Nitrogen content $/(\mu \mathrm{g} / \mathrm{g})$ & $<1$ & $<1$ & 102.3 \\
Initial boiling point $/\left({ }^{\circ} \mathrm{C}\right)$ & 186 & 165 & 169
\end{tabular}

\section{Results and Discussion}

Table 2 shows the raw spray pictures of the three fuels. The test conditions are the back pressure $1.5 \mathrm{MPa}$, the injection pressure of $100 \mathrm{MPa}$, and the injection pulse width of $0.6 \mathrm{~ms}$. It can be seen from the table that the spray is tapered. Before $0.5 \mathrm{~ms}$, the spray penetration distance increases faster and the spray profile is clearly visible. After $0.5 \mathrm{~ms}$, the spray penetration rate slows down, and the spray edge begins to appear lighter oil mist. In contrast to $0.9 \mathrm{~ms}$, the fuel spray images showed that the PD forward reached the window boundary first, and the fuel injection at $0.9 \mathrm{~ms}$ was over. 
Table 2 Spray images of different fuels (ambient pressure: 1.5 MPa, rail pressure: $100 \mathrm{MPa}$, energizing time: 0.6 $\mathrm{ms})$

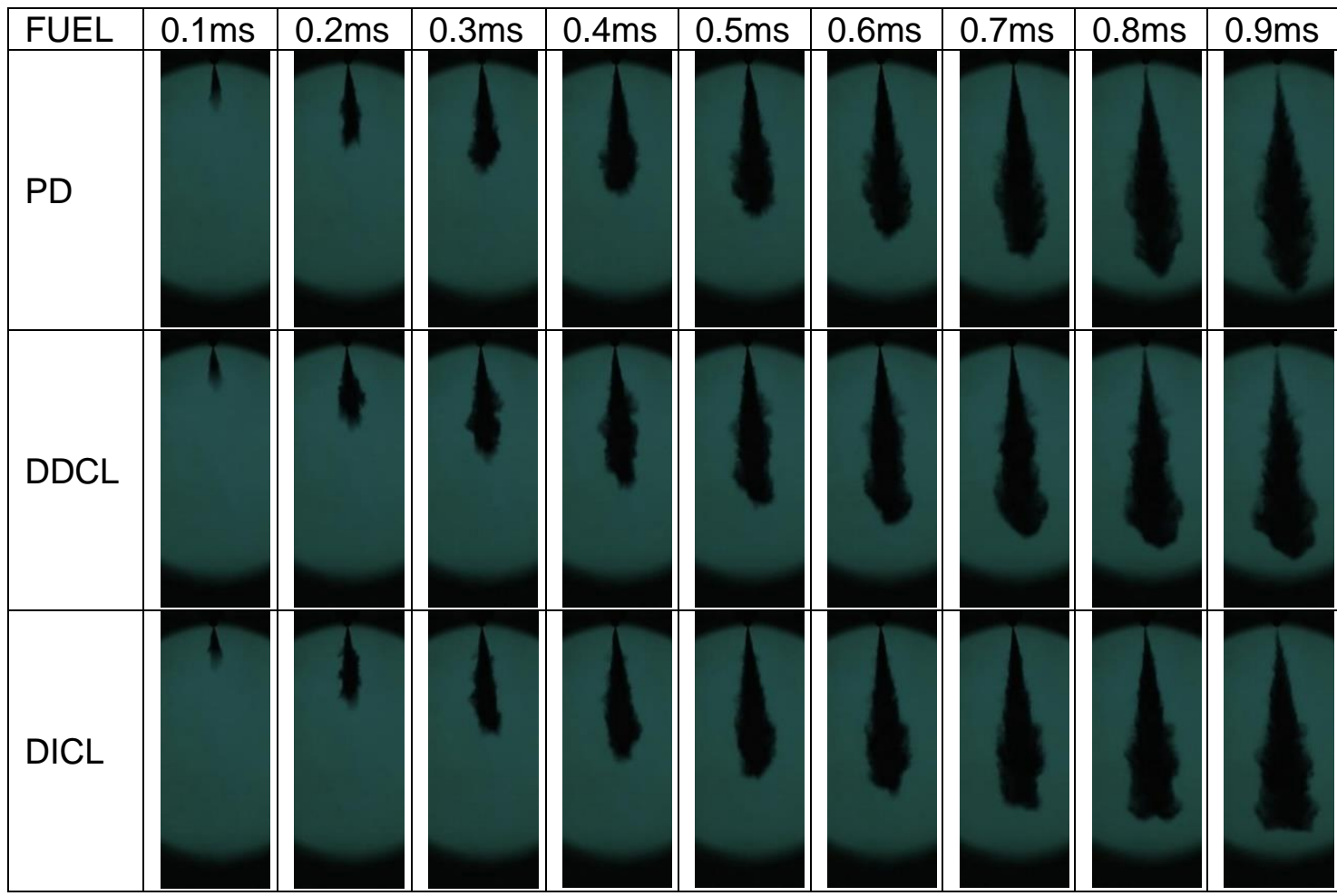

Figure 2 shows the effect of fuel type on spray characteristics. The spray characteristics of the three fuels are basically the same with time. As shown in Figure 2 (a), there is no obvious difference in the penetration distance between different fuels before $0.5 \mathrm{~ms}$. After $0.5 \mathrm{~ms}$, the spray front is far away from the nozzle, and the influence of fuel property is beginning to manifest clearly: the spray penetration from large to small is PD > DDCL > DICL. Because of its large density, PD has a large initial momentum, and itskinematic viscosity and surface tension are large, the spray is not easy to break and lose energy loss during the movement, the spray penetration is largest. However, the spray penetration of DICL is the smallest. This can be explained by that the density and surface tension of DICL are smallest. In addition, the initial boiling temperature of DICL is the lowest. The study of Naber and Siebers [11] showed that evaporation will reduce the penetration distance of the spray. Figure 2 (b) shows that the spray front speed of the three fuels increases first and then decreases. On the one hand, the momentum at the initial stage of the injection is large, the oil beam at the initial stage of the injection is not broken, and the momentum loss is low. On the other hand, when the fuel injection lasts for a certain time, the droplets at the front of the spray begin to break up, and the mixing with the ambient gas increased, leading to the increase of the resistance of the spray front. As shown in Figure 2 (c), before $0.85 \mathrm{~ms}$, the spray area of DDCL was the largest, followed by DICL, and PD was the smallest. The viscosity of DDCL is the smallest and the surface tension is small. It is easier to break into small droplets in spray process, and at the same time, the spray penetration is large. Although DICL has the smallest spray penetration, its diffusion capacity is strong, so the spray area occupies the front position. At the same time, it can be found that the spray area of fuel basically varies linearly with time before the spray area reaches the maximum. In Figure 2 (c) the spray cone angle increases first and then decreases with time. The order of spray cone angle is the same as that of spray area. It can be seen that the viscosity and surface tension of DDCL are smaller, and the oil bundles are 
easier to break and expand horizontally, so the spray cone angle is larger, while PD is just the opposite.

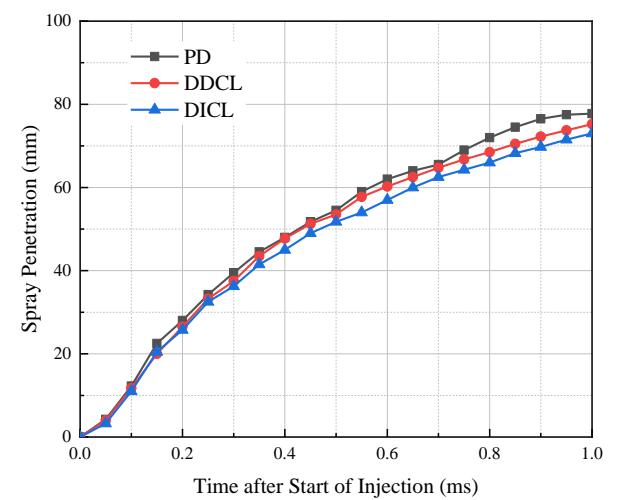

(a) Spray penetration

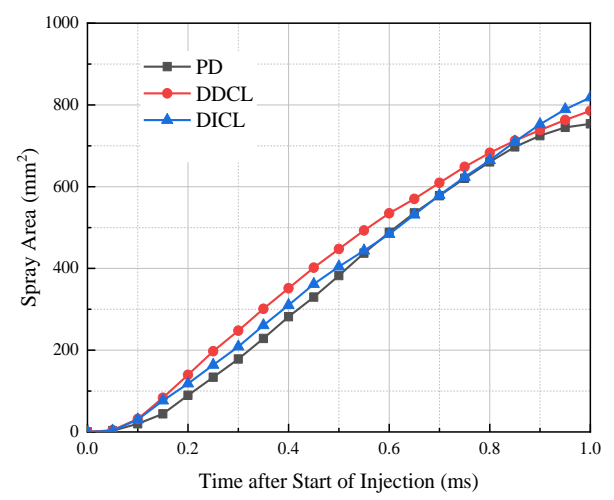

(c) spray area

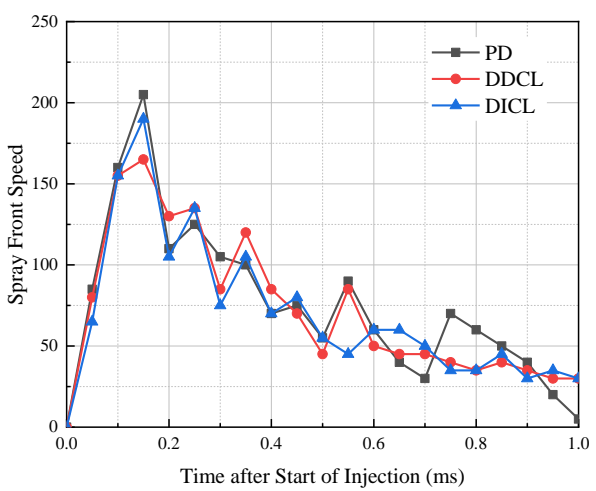

(b) spray front speed

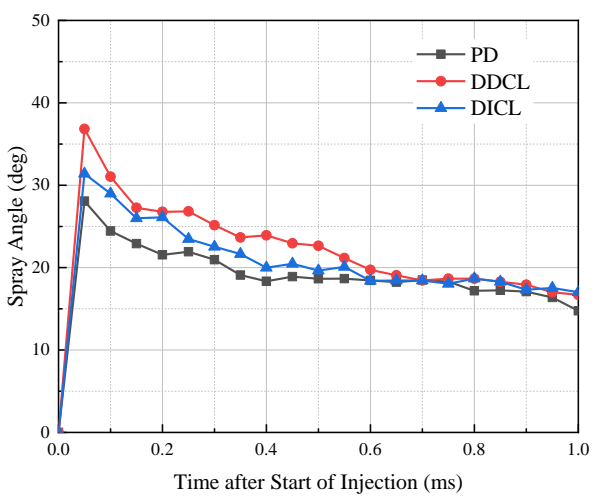

(d) spray cone angle

Figure 2 Effect of fuel types on spray characteristics (ambient pressure: 1.5 MPa, rail pressure: $100 \mathrm{MPa}$, energizing time: $0.6 \mathrm{~ms}$ )

The particle size distribution and cumulative volume distribution of CTL and PD are shown in Figure 3 (a) and (b). It can be seen from Figure 3 (a) that the droplet size distribution curves of CTL and diesel have the same trend, and the droplet diameters of spray are below $45 \mathrm{um}$. However, the curve distribution of DDCL and DICL deviates to the direction of small particles relative to $\mathrm{PD}$, which indicates that under the same working conditions, the atomization quality of CTL is better. This is due to the low viscosity and surface tension of DDCL and DICL. The cumulative volume distribution curves of DDCL and DICL are very close to each other and concentrated in the range of small droplets. In general, the atomization effect of coal liquefied diesel is better than that of diesel under the same test conditions.
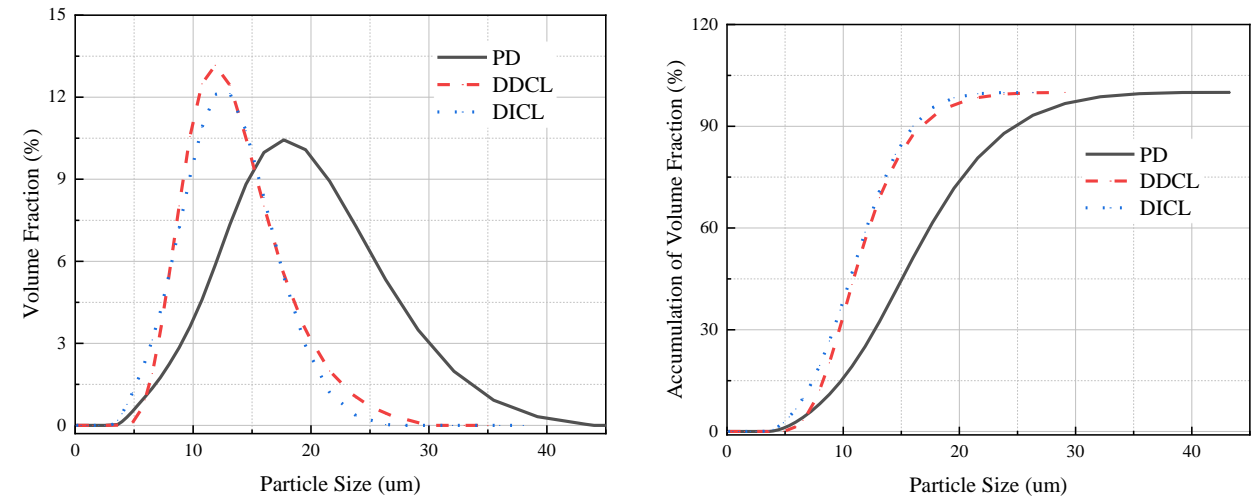

(a) Particle size distribution

(b) Particle size accumulation volume distribution 
Figure 3 Particle size distribution and accumulation volume distribution of fuel spray (ambient pressure: $1.5 \mathrm{MPa}$, rail pressure: $100 \mathrm{MPa}$, energizing time: $0.6 \mathrm{~ms}$ )

Table 3 shows the spray picture of DICL when the backpressure is $1.5 \mathrm{MPa}$ and the injection pulse width is $1.0 \mathrm{~ms}$. It can be clearly seen from the figure that the higher the injection pressure, the larger the spray penetration of DICL.

Table 3 Spray images of DICL on different rail pressure (ambient pressure: $1.5 \mathrm{MPa}$, energizing time: $1.0 \mathrm{~ms}$ )

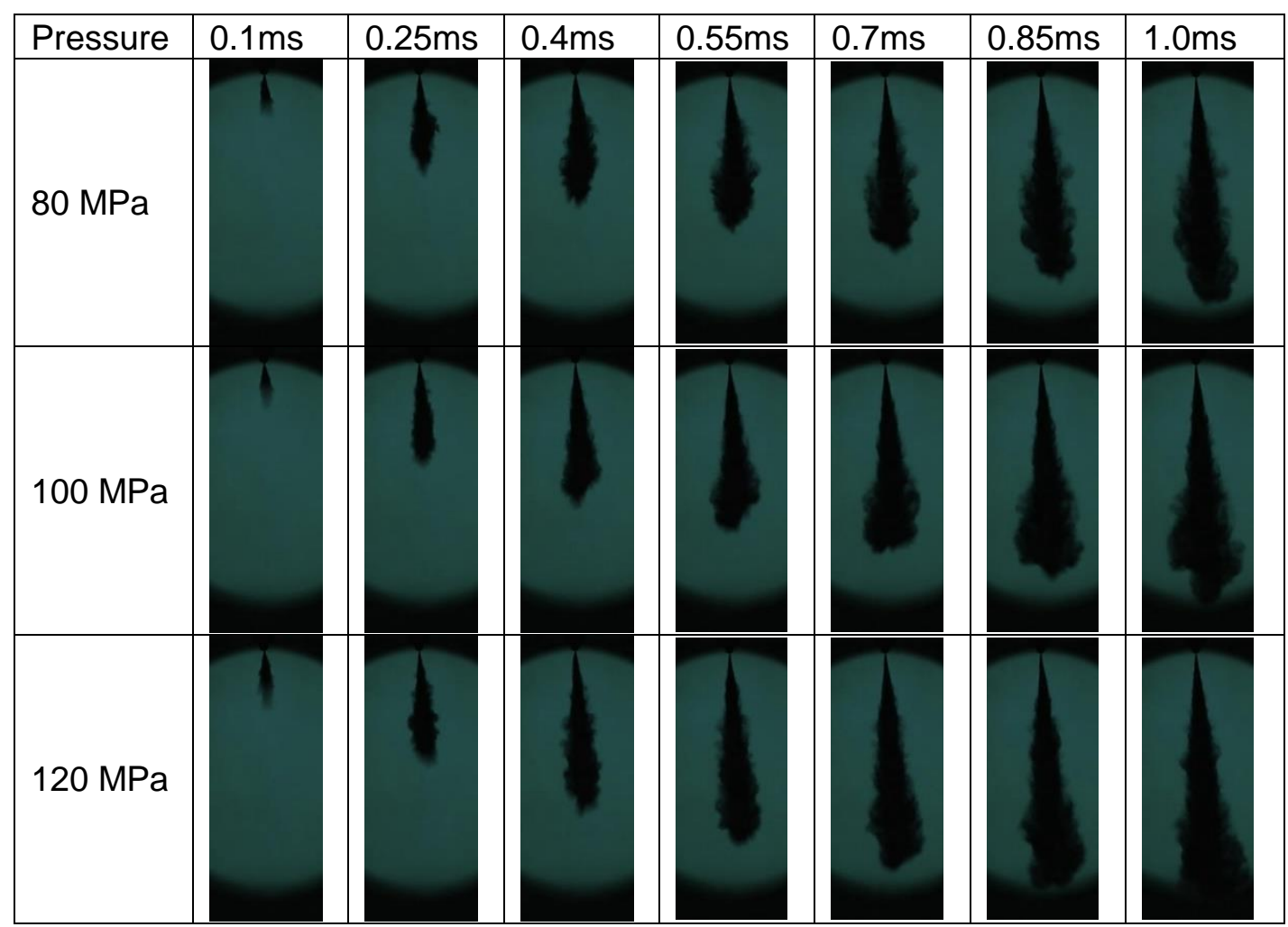

Figure 4 shows the effect of fuel injection pressure on fuel spray penetration and spray front speed. It can be seen from the graph that the spray penetration distance and the maximum velocity of the spray front increase significantly with the increase of injection pressure. It can be found that the maximum spray front speed of high rail pressure is generally 0.05 ms earlier than that of low rail pressure. This is because the higher the rail pressure, the smaller the fuel injection delay. In addition, in some cases, the maximum velocity of the spray front appears at DDCL earlier than that of PD, because the viscosity of the former is smaller than that of the latter.
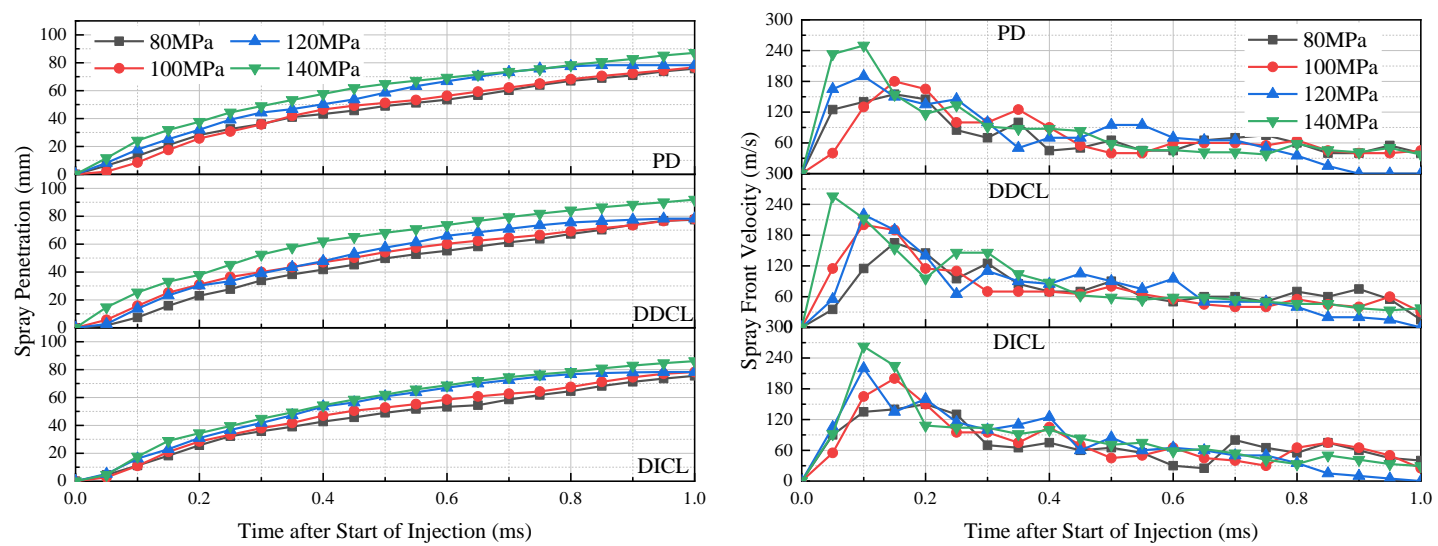
(a) spray penetration-DICL

(b) spray front speed-DICL

Figure 4 Effect of rail pressure on spray penetration and spray front velocity (ambient pressure: $1.5 \mathrm{MPa}$, energizing time: $1.0 \mathrm{~ms}$ )

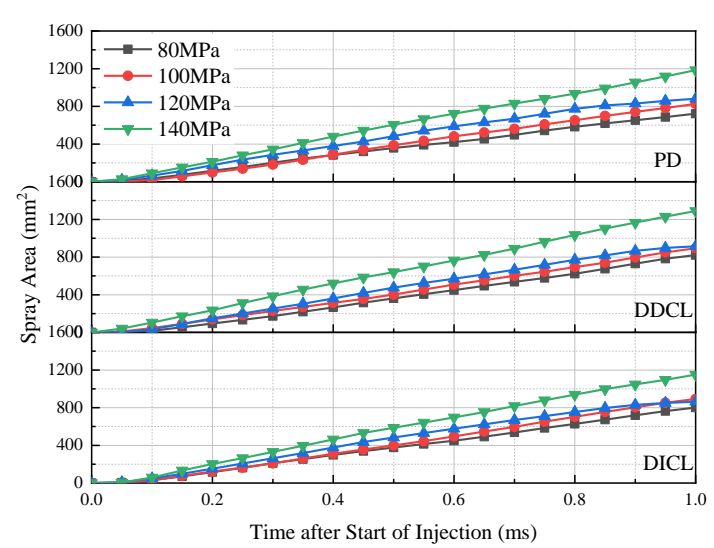

(a) spray area

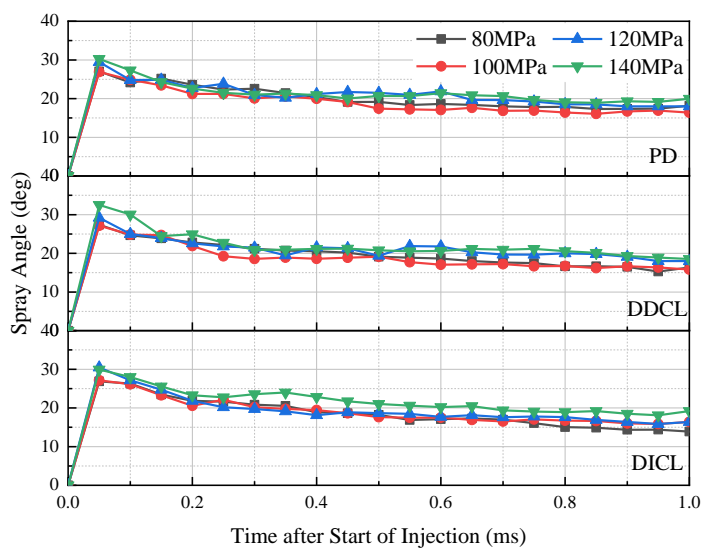

(b) spray angle

Figure 5 Effect of rail pressure on spray area and spray angle (ambient pressure: $1.5 \mathrm{MPa}$, energizing time: 1.0 $\mathrm{ms})$

As shown in Figure 5 (a), the spray area of fuel increases with the increase of rail pressure. This can be explained in two ways: On the one hand, increasing the rail pressure can increase the disturbance of the atmospheric flow, which causes the spray to break easily and radiate to the radial direction as shown in Figure 5 (b). On the other hand, the higher the pressure, the greater the spray penetration. The higher initial pressure is obtained by high injection pressure, which improves the velocity of the oil beam along the radial direction, thus enhancing the radial diffusion of the oil beam, so when the spray pressure increases, the spray cone angle increases as shown in Figure 5 (b).

\section{Conclusions}

In this paper, the effects of fuel injection pressure on the macro spray characteristics of coal liquefied diesel and diesel oil were studied by high-speed photography technology on a constant volume bomb test bench. The effects of fuel properties on the particle size were studied by using a high-speed spray particle size analyser.

The order of spray penetration is PD > DDCL > DICL. The spray front speed increases first and then decreases with time and the spray front speed of PD is the largest. The spray area of DDCL and DICL with smaller viscosity and surface tension is larger than PD. Similarly, the spray cone angle of DDCL and DICL is also larger than that of PD. The results of particle size distribution showed that the droplet diameter of DDCL and DICL is smaller than that of PD due to lower viscosity and surface tension, which indicates the atomization effect of CTL is better. With the increase of injection pressure, the spray penetration and the velocity of the spray front increased significantly. The maximum velocity of the spray front of DDCL and DBCL appears earlier than that of PD. The spray area and spray cone angle also increases with the increase of rail pressure.

\section{Acknowledgments}

The authors would like to acknowledge the financial supports provided by the National Key Research and Development Project of China (No.2017YFE0130800) and the National Natural Science Foundation of China (No. 91741122).

\section{Nomenclature}


$P D \quad$ petroleum diesel

CTL coal to liquid

$D D C L$ diesel from direct coal liquefaction

DICL diesel from indirect coal liquefaction

\section{References}

[1] Dinesha P, Nayak V and Mohanan P. Effect of oxygen enrichment on the performance, combustion, and emission of single cylinder stationary $\mathrm{Cl}$ engine fueled with cardanol diesel blends. J Mech Sci Technol 2014; 28(7): 2919-2924.

[2] British Petroleum Statistical Review of World Energy, 66th edition (2020) https://www.bp.com/content/dam/bp/business-sites/en/global/corporate/pdfs/energyeconomics/statistical-review/bp-stats-review-2020-full-report.pdf.

[3] British Petroleum (2020) The growth of energy used in transportation slows, with oil peaking in mid- to late-2020s https://www.bp.com/en/global/corporate/energy-economics/energyoutlook/demand-by-sector/transport.html.

[4] Yang S, Xiao Z, Deng C, et al. Techno-economic analysis of coal-to-liquid processes with different gasifier alternatives. J Clean Prod 2020; 253: 120006.

[5] Höök $\mathrm{M}$ and Aleklett $\mathrm{K}$. A review on coal-to-liquid fuels and its coal consumption. Int $\mathrm{J}$ Energ Res 2010; 34: 848-864.

[6] HIROYASU H, ARAI M. Structures of Fuel Sprays in Diesel Engines[J]. 1990.

[7] CHEN S K. Spray Cone Angles of Effervescent Atomizers[J]. Atomization \& Sprays, 1994,4(3):291-301.

[8] El-BESHBEESHY M S T F. Fuel Effects on Spray Characteristics by Light Extinction Technique: The Combustion Institute Central Atate Meeting, 1994[C].

[9] TABATA. Effect of Fuel Viscosity and Surface Tension on Diesel Spray Drops[J]. ICLASS, 1985.

[10] CHANG C T, FARRELL P V. A study on the effects of fuel viscosity and nozzle geometry on high injection pressure diesel spray characteristics[J]. Sae Technical Papers, 1997,117(1):133-136.

[11] NABER J D, SIEBERS D L. Effects of Gas Density and Vaporization on Penetration and Dispersion of Diesel Sprays[J]. Sae Technical Papers, 1996,105(3):82-111. 